\title{
The Previously Unidentified, Divergent Badnavirus Species Cacao red vein-banding virus is Associated with Cacao Swollen Shoot Disease in Nigeria
}

\author{
Nomatter Chingandu, ${ }^{1}$ Lelia Dongo, ${ }^{2}$ Osman A. Gutierrez, ${ }^{3}$ and Judith K. Brown ${ }^{1, \dagger}$ \\ ${ }^{1}$ School of Plant Sciences, The University of Arizona, Tucson 85721 U.S.A.; ${ }^{2}$ Cocoa Research Institute of Nigeria, Ibadan, \\ Nigeria; and ${ }^{3}$ United States Department of Agriculture-Agricultural Research Service Subtropical Horticultural Research Station, \\ Miami, FL 33158 U.S.A.
}

\begin{abstract}
Cacao swollen shoot disease (CSSD) of Theobroma cacao was reported in Nigeria in 1944; however, no badnaviral genome sequences have been found associated with the symptomatic trees. In 2017, leaf samples $(n=$ 18) were collected from cacao trees from Osun and Oyo, Nigeria showing foliar symptoms that included red vein-banding and shoot swelling, and variable secondary mosaic, mottling, and fern-like pattern symptoms. Abutting primers designed around previously determined 500-bp intergenic region sequences were used for polymerase chain reaction (PCR) amplification. Of the 18 samples, 9 yielded an approximately 7,000$\mathrm{bp}$, apparently genome-size product. The nine genomes were sequenced and found to encode four open reading frames, and to share 86 to $99 \%$ nucleotide identity. Pairwise analysis of the Nigerian genomes with 21

previously reported CSSD badnaviruses, at the complete genome and reverse-transcription ribonuclease $\mathrm{H}(1,230 \mathrm{bp})$ sequence levels, indicated 71 to 75 and 72 to $76 \%$ nucleotide identity, respectively. Phylogenetic analysis of the nine complete genomes indicated that the closest relatives of the divergent Nigerian isolates were previously described West African CSSD badnaviruses. Based on pairwise comparisons and phylogenetic analyses, the Nigerian CSSD isolates constitute a previously unrecognized Badnavirus sp., herein named Cacao red veinbanding virus (CRVBV). Primers designed based on the CRVBV genome sequences amplified a 1,068-bp fragment from 16 of 18 field samples tested by PCR, suggesting the possible existence of additional CRVBV variants.
\end{abstract}

Cacao swollen shoot disease (CSSD) of cacao Theobroma cacao (L.), the source of cacao beans used for chocolate and other economically important food products and cosmetics, is among the most important diseases of cacao in West Africa (Ploetz 2007), where approximately $75 \%$ of the world's cacao is grown (Bartley 2005). Diseased trees develop a range of different symptoms, including fern patterning, red vein banding of leaves, swollen shoots on tree branches and lateral shoots (suckers), and, sometimes, deformed cacao pods. Compared with healthy trees, CSSD-diseased trees produce fewer pods, with yields reduced by $50 \%$ or more (Posnette 1950; Steven 1936). The disease was first reported in cacao trees in Ghana during 1936 (Steven 1936) and then in Nigeria (Murray 1945), Ivory Coast (Mangenot et al. 1946), and Togo (Partiot et al. 1978).

Until recently, CSSD was thought to be caused by different strains of Cacao swollen shoot virus (CSSV). The availability of complete

${ }^{\dagger}$ Corresponding author: J. K. Brown; E-mail: jbrown@ag.arizona.edu

Funding: N. Chingandu and J. K. Brown acknowledge the United States Department of Agriculture-Agricultural Research Service (USDA-ARS) for supporting this research through a Non-Assistance Cooperative Agreement number 6038-21000-023-13-S: "Determining Cacao swollen shoot virus diversity, distribution, epidemiology and tool design", and MARS Inc. for providing support through the USDA-ARS-MARS Trust Agreement number 6038-21000-023-12-T: "Genomic Enhancement of Theobroma cacao". L. Dongo and J. K. Brown acknowledge the generous support provided by the USDA-Foreign Agricultural Service and World Cocoa Foundation-Borlaug Fellowship.

*The $\boldsymbol{e}$-Xtra logo stands for "electronic extra" and indicates that one supplementary table is published online.

The author(s) declare no conflict of interest.

Accepted for publication 27 December 2018.

@ 2019 The American Phytopathological Society genome sequences for a number of isolates has led to the recognition by the International Committee on the Taxonomy of Viruses (ICTV) of Cacao swollen shoot CD virus (CSSCDV) and Cacao swollen shoot Togo A virus (CSSTAV) as distinct species (Kouakou et al. 2012; Muller 2015; Muller and Sackey 2005). The CSSDassociated badnaviruses recognized thus far include three ICTVapproved and one proposed species (Cacao red vein virus [CRVV], CSSCDV, CSSTAV, and CSSV) occurring in Cote d'Ivoire, Ghana, or Togo (Chingandu et al. 2017b; Muller 2015). Most recently, CRVV, which has been associated with rapid-decline in Ghana and Cote d'Ivoire (Chingandu et al. 2017a), and Cacao red veinbanding virus (CRVBV) from Nigeria (Dongo et al. 2018) (this report) have been described as new, provisional species. Although CSSV is thought to be the most widely distributed species in West Africa, only a relatively small number of samples have been analyzed overall, making this conclusion preliminary. Nevertheless, conclusive evidence has not been provided to demonstrate the presence or absence of virus-like particles in naturally infected symptomatic cacao plants, from which badnaviral genome sequences have been determined. However, bacilliform particles were observed by immunosorbent electron microscopy in cacao plants inoculated with an infectious clone by particle-bombardment (Hagen et al. 1994).

The CSSD-associated badnaviruses belong to the genus Badnavirus, family Caulimoviridae. Badnaviruses have a circular, doublestranded (ds)DNA genome of 6.8 to $9.2 \mathrm{kbp}$ in size (Geering 2014). The dsDNA genome is encapsidated in a nonenveloped bacilliform particle, and encodes three to seven open reading frames (ORFs), including ORFs 1, 2, and 3, which are characteristic of all other badnaviruses. Although the function of the ORF1-encoded protein has not been determined, for CSSV, ORF2 encodes a nucleic acid-binding protein (Jacquot et al. 1996). The ORF3 is best characterized and encodes a large polyprotein that is cleaved by viralaspartate protease to derive movement protein (MP), coat protein (CP), aspartate protease (AP), reverse transcription (RT), and ribonuclease $\mathrm{H}$ (RNase H) (Geering 2014). The function has not been determined for the additional two to three predicted ORFs, encoded by several other CSSD badnaviruses (Chingandu et al. 2017b). 
Members of the CSSD complex are reported to be transmitted by 15 or more mealybug species, with transmission occurring in a semipersistent manner, and virus retention by the vector for 3 to 6 days (Obok et al. 2018; Posnette and Strickland 1948; Roivainen 1976). Studies have shown that CSSD-associated badnaviruses are not transmitted by pollen or through true seed (Ameyaw et al. 2013; Quainoo et al. 2008); however, experimentally, the virus can be transmitted by grafting, or by sap inoculation with great difficulty (Brunt 1964).

Despite the recognition of at least five CSSD badnaviral species, Koch's postulates have been completed for only a single CSSV cloned genome, which has been delivered to test plants by particle bombardment (Hagen et al. 1994), or by Agrobacterium-mediated inoculation (Friscina et al. 2017; Jacquot et al. 1999). Thus, the basis for the variation in secondary foliar or shoot-swelling symptoms observed for presumed, CSSD badnavirus-infected cacao trees has not been determined for the majority of species and CSSV strains. Also, whether each CSSD Badnavirus sp. causes its own unique symptom in cacao plants upon infection, or whether the diverse phenotypes observed are cacao genotype-virus specific, is not known. Even so, cacao breeding programs in West Africa would greatly benefit from such knowledge, given the many challenges involved in identifying and deploying durable genetic resistance to the CSSD complex (Attafuah and Glendinning 1965a,b; Kenten and Legg 1970; Posnette and Todd 1951).

Until recently, CSSD virus detection in cacao relied on an enzymelinked immunosorbent assay (ELISA) developed for a CSSV isolate from Ghana (Sagemann et al. 1983). Polymerase chain reaction (PCR) detection assays have been developed for CSSD badnaviruses; however, their success has been largely constrained by the limited number of CSSD genome sequences available to guide primer design (Chingandu et al. 2017b; Dongo and Orisajo 2007; Edward and Wetten 2016; Kouakou et al. 2012; Muller et al. 2001). In Nigeria, only $7 \%$ of the cacao samples tested using the "universal" Badna-F/R primers (Yang et al. 2003) were positive for virus, despite the presence of virus-like symptoms (Dongo et al. 2012). Furthermore, the PCR primers based on ORF1- and ORF2-flanking sequences, or several loci in ORF3 (for example, the AP, MP, RT, and RT-RNase H regions), were found to have only a limited capacity for CSSD badnavirus detection (Abrokwah et al. 2016; Chingandu et al. 2017b; Kouakou et al. 2012; Oro et al. 2012). Most recently, primers based on 14 newly determined genome sequences, and 7 genome sequences available in GenBank, showed increased frequency of badnavirus detection over primers tested previously; however, suspect virus was not detectable in at least 30 to $35 \%$ of the samples, despite the presence of characteristic CSSD symptoms (Ameyaw et al. 2018; Chingandu et al. 2017a). Furthermore, badnavirus was not detectable using most of the latter primers in PCR amplification of symptomatic samples collected from Nigeria during 2017 (unpublished results). This result is supported by previous reports that CSSD-like symptoms in Nigeria are distinct from those observed in Ghana and Cote d'Ivoire (Dongo et al. 2012; Lister and Thresh 1956).

In Nigeria, CSSD symptoms in cacao plantations were documented for the first time in 1944, near Ibadan, Oyo State (Murray 1945). Red vein-banding was the most common and widespread symptom observed on the flushing leaves (Thresh 1960), which may be ephemeral or persistent (personal observation). Other symptoms consisted of foliar discolorations involving variable patterns and, rarely, shoot swellings, characteristic of CSSD in Cote d'Ivoire and Ghana. Initially, CSSD in Nigerian cacao was considered "mild" by comparison with the New Juaben strain from Ghana that exhibited a "severe" phenotype (Ollennu and Owusu 2003). As a result, it has been postulated that the swollen shoot disease of cacao in Nigeria may involve one or more unique Badnavirus spp. or strains (Adegbola 1975; Dongo et al. 2012; Lister and Thresh 1956,1957). Despite the removal of $>1$ million trees during 1946 to 1956 (Lister and Thresh 1957; Thresh 1958) the disease continued to spread to most cacao-growing regions of Nigeria.

The objective of this study was to identify and characterize at the genomic level the CSSD badnaviruses found to be associated with symptomatic cacao trees in Nigeria, undetectable by ELISA, or by
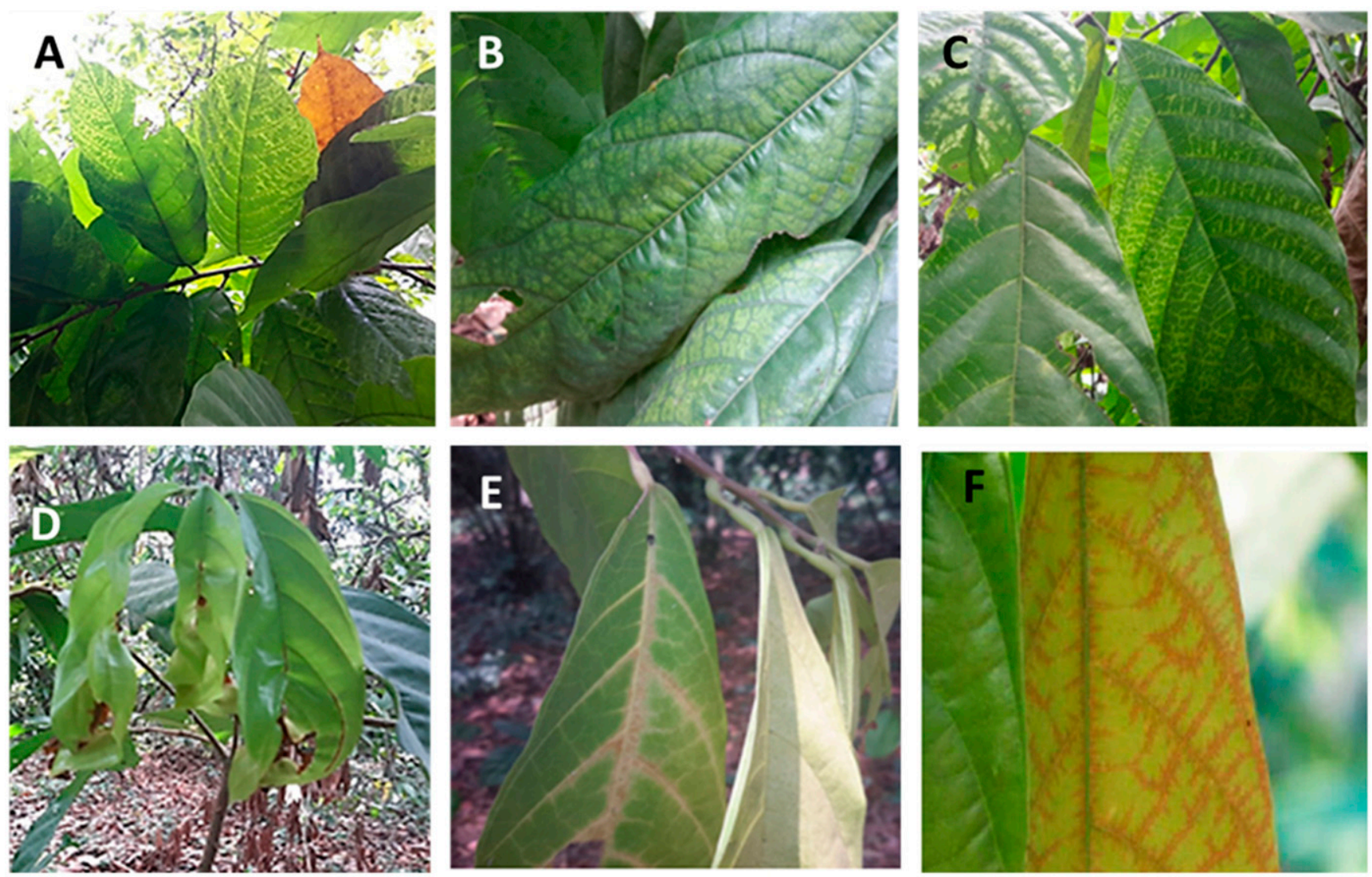

Fig. 1. Different foliar symptoms observed in cacao trees in Oyo and Osun States in Nigeria that were associated with Cacao red vein-banding virus, including examples of A, fern pattern; B, chlorotic mottling; C, vein clearing; D, necrotic crinkling; E, chlorosis; and F, red vein-banding. 
PCR amplification until recently. This was accomplished by carrying out PCR amplification and DNA sequencing for nine complete CSSD badnaviral genomes from Nigeria, followed by development of a specific diagnostic assay based on the determined genomic sequences. Sequence analysis of the newly determined genome sequences revealed a previously unidentified badnaviral species (herein CRVBV). This new species represents the fifth badnavirus in the putative badnaviral complex known to be associated with CSSD of cacao in West Africa.

\section{Materials and Methods}

Plant samples. Cacao leaf samples showing red vein-banding symptoms on flush growth leaves (Fig. 1) and diverse foliar symptoms, including fern patterns, chlorotic mottling, and vein clearing (Fig. 1; Supplementary Table S1), were collected from nine trees each in the states of Oyo and Osun, Nigeria during March 2017. The samples were selected to represent the range of different foliar symptoms observed in CSSD cacao trees in Nigeria. Leaf samples were transferred to 50-ml screwcap tubes containing $100 \%$ glycerol.

DNA isolation and primer design. Total DNA was purified from leaf samples $(100 \mathrm{mg})$ using the cetyltrimethylammonium bromide method (Doyle and Doyle 1990) and stored at $-20^{\circ} \mathrm{C}$. The initial detection was carried out by PCR amplification using primers designed previously for CSSD badnavirus detection intended to target CSSD badnavirus isolates in Cote d'Ivoire and Ghana (Chingandu et al. 2017a; Kouakou et al. 2012). Of the nine samples, a PCR amplicon was obtained for a fragment of the intergenic region (IR). Phylogenetic analysis of the aligned fragments by neighbor-joining, implemented in MEGA 6 (Tamura et al. 2013), revealed two subgroups of variants, which grouped by the state in Nigeria from which the samples were collected (origin Osun or Oyo). A preliminary report of these results has been published recently (Dongo et al. 2018). Based on the IR sequences, an abutting primer pair was designed for each subgroup. Primers for amplification of the Osun isolates were NIG5_F-5-ATCCACTAGTTCTAGAACAGTTACAAAGG ACGG-3' and NIG5_R 5'-TGGCGGCCGCTCTAGACTCTCTGG TTGTATGAAGG-3, whereas the Oyo isolate primers were NIG18_F 5'-GCTTGATATCGAATTCTAAGCATTAGGTTTTCT

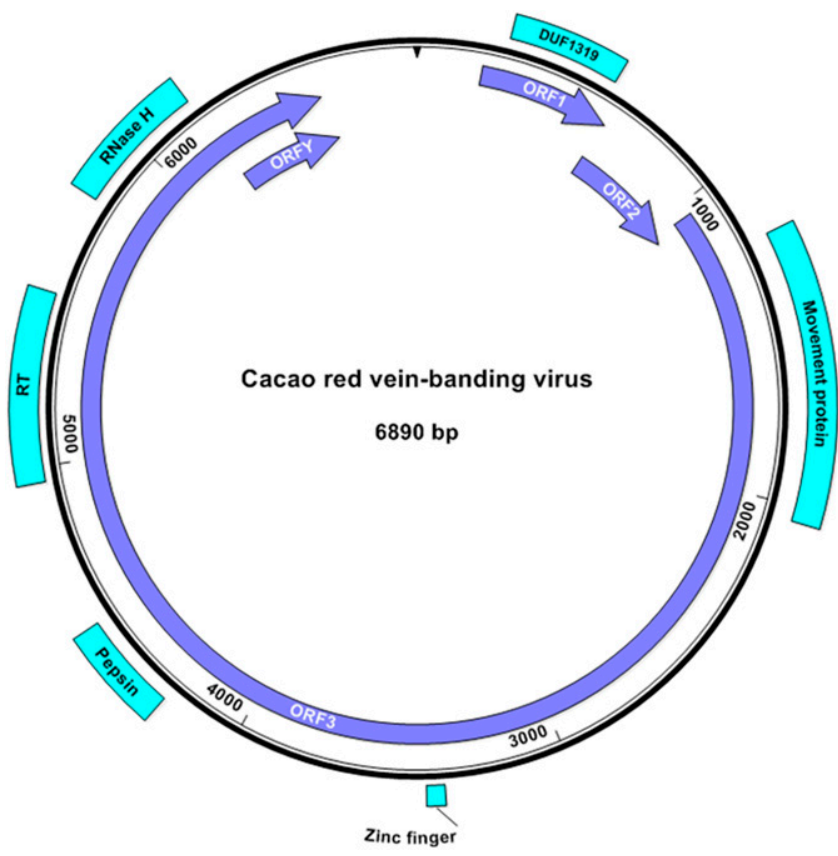

Fig. 2. Genome organization map for a representative Cacao red vein-banding virus genome sequence determined from nine cacao swollen shoot disease-associated cacao trees in Nigeria. Predicted open reading frames of $>10 \mathrm{kDa}$ in size are shown as solid arrows. Relative positions of the predicted conserved protein domains are indicated by boxes. Abbreviations for the predicted conserved protein domains: DUF = domain of unknown function; Pepsin = pepsin-like aspartate protease; $\mathrm{RT}$ = reverse transcription; and RNase $\mathrm{H}=$ ribonuclease $\mathrm{H}$.
CTTG-3' and NIG18_R 5'-CGGGCTGCAGGAATTCAGCTTC GATATTTTCGAGTC-3'. The italicized bases in each primer sequence represent the pGreen II 0000 plasmid vector, contained within the primer to facilitate cloning of the resultant amplicons, and the underlined bases indicate the restriction site used for cloning.

PCR amplification and molecular cloning. The PCR consisted of 1× CloneAmp HiFi PCR Premix (Clontech, Mountain View, CA, U.S.A.), $0.2 \mu \mathrm{M}$ each reverse and forward primer, $2 \mu \mathrm{l}$ containing 60 to $120 \mathrm{ng}$ of total DNA, and nuclease-free water, to a final volume of $50 \mu$ l. The cycling parameters were denaturation at $98^{\circ} \mathrm{C}$ for $2 \mathrm{~min}$; followed by 40 cycles of denaturation at $98^{\circ} \mathrm{C}$ for $20 \mathrm{~s}$, annealing at $55^{\circ} \mathrm{C}$ for $15 \mathrm{~s}$, and extension at $72^{\circ} \mathrm{C}$ for $8 \mathrm{~min}$; and a final extension at $72{ }^{\circ} \mathrm{C}$ for $10 \mathrm{~min}$. The amplicons were separated by agarose gel $(0.8 \%)$ stained with GelGreen $(10 \mu \mathrm{l} / \mathrm{ml})$ stain (Biotium, Fremont, CA, U.S.A.) in $1 \times$ Tris-acetate EDTA (TAE) buffer, $\mathrm{pH} 8.0$, to estimate amplicon size. The DNA bands of approximately $7 \mathrm{kbp}$ in size were excised and gel purified using the Illustra GFX PCR and DNA Gel Band Purification kit (GE Healthcare Bio-Sciences, Pittsburgh, PA, U.S.A.), according to the manufacturer's instructions.

The concentration of gel-eluted DNA was determined using the Nanodrop 2000 UV-Vis spectrophotometer (Thermo-Fisher Scientific, Waltham, MA, U.S.A.). Viral amplicons of the expected size were cloned into the pGreen II 0000 plasmid vector, previously linearized by digestion with XbaI (NIG5_F/R) and EcoRI (NIG18_F/R) (New England Biolabs, Ipswich, MA, U.S.A.). Transformation was carried out using the In-Fusion HD Cloning kit (Clontech), with the manufacturer's instructions.

The insert size of each cloned amplicon was confirmed following purification of the plasmid vector with the GeneJET Plasmid Miniprep Kit (Thermo Fisher Scientific, Waltham, MA, U.S.A.), and by restriction digestion with $X b a \mathrm{I}$ and EcoRI. The DNA sequence was determined for the cloned inserts of the expected size at approximately $7 \mathrm{kbp}$, using bidirectional, capillary (Sanger) DNA sequencing, with primer walking for an overlap of approximately $200 \mathrm{bp}$ (Eton Bioscience, San Diego, CA, U.S.A.). Sequences were assembled using the SeqMan Pro v.12 software (DNASTAR).

Genome sequence analyses. The complete genome sequences were subjected to pairwise nucleotide identity and phylogenetic analysis. The 1,230-bp fragment of the RT-RNase H region, approved by the ICTV for species demarcation in the genus Badnavirus (King et al. 2012), was subjected to the same analyses. The 65 badnavirus sequences, representing 57 putative species, that were available in the GenBank database were downloaded and included together with the 9 sequences determined herein in the analyses, totaling 74 sequences. Sequences were aligned using MUSCLE (Edgar 2004), implemented in CLC Sequence Viewer 8, and subjected to pairwise distance analysis using the Sequence Demarcation Tool v1.2 (Muhire et al. 2014).

Phylogenetic analysis was carried out for the 74 genome sequences using the maximum-likelihood (ML) algorithm, implemented in MEGA 6 (Tamura et al. 2013). The ML tree was reconstructed using the general time reversible model and $\gamma$ distribution with invariable sites for 1,000 bootstrap replicates, and clades having statistically significant node support, at $\geq 70 \%$, were included on the ML tree.

The predicted ORFs were identified for the nine apparently fulllength badnaviral genomes, using the NCBI ORF finder tool and standard genetic code, with a minimum ORF size of $>50$ amino acids. The locations and identities of the conserved badnaviral domains were predicted using the NCBI Conserved Domain Database (CDD) search tool (Marchler-Bauer et al. 2015).

Specific primer design and confirmation. Based on an ML alignment of the nine newly determined CRVBV genome sequences of the Nigerian isolates, a primer pair was designed to amplify a fragment located between coordinates 1,734 and 2,802. The primer sequences NIG_F 5'-AATCACAAGAAGTATGACAGGGAG-3' and NIG_R 5'-TTCATTCGCCATTGTATCCAC-3' were used for PCR amplification of a product of an expected size of 1,068 bp from total DNA isolated from the 18 collected cacao samples collected in 
Nigeria during 2017. The PCR contained 1× RedTaq Ready Mix (Sigma-Aldrich, St. Louis, MO, U.S.A.), $0.2 \mu \mathrm{M}$ each reverse and forward primer, $1 \mu \mathrm{l}$ of the total DNA, and nuclease-free water to a total volume of $25 \mu \mathrm{l}$. The cycling parameters consisted of initial denaturation at $98^{\circ} \mathrm{C}$ for $2 \mathrm{~min}$; followed by 35 cycles of denaturation at $98^{\circ} \mathrm{C}$ for $20 \mathrm{~s}$, annealing at $55^{\circ} \mathrm{C}$ for $15 \mathrm{~s}$, and extension at $72^{\circ} \mathrm{C}$ for $30 \mathrm{~s}$; with a final extension at $72^{\circ} \mathrm{C}$ for $5 \mathrm{~min}$. The PCR products were separated by electrophoresis on a $0.8 \%$ agarose gel in $1 \times$ TAE buffer, $\mathrm{pH}$ 8.0. Bands were visualized by GelRed staining at $10 \mu \mathrm{l} / \mathrm{ml}$ (Biotium).

The amplicons of the expected size (1,068 bp) were ligated into the pGEM T-Easy plasmid vector (Promega Corp., Madison, WI, U.S.A.) and transformed into DH5 $\alpha$ Escherichia coli competent cells, according to the manufacturer's instructions. The approximate size of each insert was determined by colony PCR for three or more white colonies per ligation or transformation reaction, using universal M13_F/R primers. Two plasmids per clone, each bearing an insert of the expected-size amplicon, were selected and sequenced as described above. Sequences were manually edited based on the electropherogram, assembled, and trimmed using SeqMan Pro v.12 (DNASTAR). The resultant sequences for cloned amplicons were aligned and subjected to ML analysis, as described previously.

\section{Results}

DNA sequencing and BLASTn analyses. The abutting primers used to amplify CSSD badnaviral genome sequences yielded an approximately 7.0-kbp product from 9 of 18 samples. The BLASTn searches indicated that the closest matches were the four CSSD badnaviruses known previously from West Africa-CSSCDV, CRVV, CSSTAV and CSSV-with BLASTn similarity scores of 71 to $77 \%$ and 76 to $99 \%$ coverage. The CSSD badnavirus-like genome sequences were 6,820 to 6,933 bp in size, making them somewhat shorter than previously reported CSSD badnaviral genomes, at approximately 7,000 to 7,300 bp in size. The nine genome sequences were deposited in the GenBank database as accession numbers MH029281 and MH029282 for NIG5 and NIG18 isolates, respectively, and MH785297 to MH785303 for the other seven isolates.

Predicted genome arrangement. All nine of the CSSD badnaviral genome sequences from Nigeria encoded the predicted coding and noncoding regions known for previously characterized badnaviruses. The tRNA ${ }^{\text {met }}$ binding site, TGGTATCAGAGC, was located at the nucleotide coordinates 1 to 12 , whereas the TATA box was located between nucleotide coordinates 6,811 and 6,816 . Four coding regions were identified, consisting of predicted ORFs 1, 2, 3, and Y, while there was no detectable ORFX within the nine genomes (Fig. 2). ORF1 and ORFY, of 143 and 130 amino acid (aa) in size, respectively, were similar in size to the four previously described CSSD Badnavirus spp. The slightly smaller genome size for the isolates from Nigeria can be accounted for based the size of ORF3, which is 18 to 23 aa smaller than the analogous coding region for previously studied CSSD badnaviruses of 1,823 to 1,856 aa in size. Although, in the genomes of the Nigerian isolates, certain bases were absent (deletions) that are otherwise present in previously characterized CSSD badnaviral species, the predicted conserved protein domains (CPDs) were highly conserved among members of the entire CSSD complex, including the Nigerian isolates (Fig. 2).

CPDs. Using the NCBI CDD tool for analysis, five CPDs were identified in all nine genomes, and they were similar to those reported for other badnaviruses; and, in particular, they were reminiscent of the CPDs found in the four previously reported species of CSSD badnaviruses (Fig. 2) (Chingandu et al. 2017b). The predicted CPDs consisted of a domain of unknown function (DUF), DUF1319 on ORF1,

\begin{tabular}{|c|c|c|c|c|c|c|c|c|c|c|c|c|c|c|c|c|c|c|c|c|c|c|c|c|c|c|c|c|c|c|}
\hline NIG1 - CRVBV & 100 & & & & & & & & & & & & & & & & & & & & & & & & & & & & & \\
\hline NIG9 - CRVBV & 99 & 100 & & & & & & & & & & & & & & & & & & & & & & & & & & & & \\
\hline NIG5 - CRVBV & 99 & 100 & 100 & & & & & & & & & & & & & & & & & & & & & & & & & & & \\
\hline NIG7 - CRVBV & 98 & 98 & 99 & 100 & & & & & & & & & & & & & & & & & & & & & & & & & & \\
\hline NIG12 - CRVBV & 88 & 88 & 88 & 87 & 100 & & & & & & & & & & & & & & & & & & & & & & & & & \\
\hline NIG13 - CRVBV & 88 & 88 & 88 & 88 & 98 & 100 & & & & & & & & & & & & & & & & & & & & & & & & \\
\hline NIG10 - CRVBV & 88 & 88 & 88 & 88 & 98 & 100 & 100 & & & & & & & & & & & & & & & & & & & & & & & \\
\hline NIG16 - CRVBV & 88 & 87 & 88 & 87 & 97 & 97 & 97 & 100 & & & & & & & & & & & & & & & & & & & & & & \\
\hline NIG18 - CRVBV & 88 & 88 & 88 & 88 & 98 & 97 & 97 & 99 & 100 & & & & & & & & & & & & & & & & & & & & & \\
\hline CI-JN606110 - CSSCDV & 73 & 73 & 74 & 74 & 74 & 75 & 75 & 74 & 74 & 100 & & & & & & & & & & & & & & & & & & & & \\
\hline TG-AJ781003- CSSTAV & 74 & 74 & 74 & 74 & 76 & 75 & 75 & 75 & 75 & 76 & 100 & & & & & & & & & & & & & & & & & & & \\
\hline Cl-KX592584- CRVV & 72 & 73 & 73 & 73 & 75 & 75 & 75 & 75 & 75 & 72 & 75 & 100 & & & & & & & & & & & & & & & & & & \\
\hline GH-KX592571- CRVV & 74 & 74 & 74 & 74 & 75 & 75 & 75 & 75 & 75 & 73 & 75 & 84 & 100 & & & & & & & & & & & & & & & & & \\
\hline Cl-KX592572- CRVV & 73 & 74 & 74 & 74 & 76 & 76 & 76 & 76 & 76 & 73 & 75 & 83 & 86 & 100 & & & & & & & & & & & & & & & & \\
\hline GH-KX592573- CRVV & 74 & 74 & 74 & 74 & 75 & 76 & 76 & 76 & 75 & 73 & 75 & 82 & 82 & 82 & 100 & & & & & & & & & & & & & & & \\
\hline TG-L14546- CSSV & 74 & 74 & 74 & 74 & 75 & 75 & 75 & 75 & 75 & 75 & 75 & 75 & 76 & 76 & 76 & 100 & & & & & & & & & & & & & & \\
\hline TG-AJ534983- CSSV & 74 & 74 & 74 & 74 & 75 & 75 & 75 & 75 & 75 & 75 & 75 & 76 & 76 & 76 & 76 & 98 & 100 & & & & & & & & & & & & & \\
\hline Cl-KX592574- CSSV & 75 & 75 & 75 & 75 & 75 & 76 & 76 & 75 & 76 & 75 & 75 & 76 & 77 & 76 & 75 & 88 & 88 & 100 & & & & & & & & & & & & \\
\hline Cl-KX592579- CSSV & 74 & 74 & 74 & 74 & 75 & 75 & 75 & 75 & 75 & 75 & 75 & 76 & 76 & 76 & 75 & 90 & 90 & 93 & 100 & & & & & & & & & & & \\
\hline Cl-KX592577- CSSV & 75 & 75 & 75 & 74 & 75 & 75 & 75 & 75 & 75 & 75 & 75 & 76 & 76 & 76 & 75 & 90 & 91 & 93 & 99 & 100 & & & & & & & & & & \\
\hline GH-AJ609020- CSSV & 74 & 74 & 75 & 74 & 75 & 75 & 75 & 74 & 75 & 75 & 75 & 76 & 76 & 75 & 75 & 89 & 90 & 92 & 98 & 98 & 100 & & & & & & & & & \\
\hline GH-AJ609019- CSSV & 74 & 74 & 75 & 74 & 75 & 75 & 75 & 75 & 75 & 75 & 75 & 76 & 76 & 76 & 75 & 90 & 90 & 92 & 98 & 98 & 98 & 100 & & & & & & & & \\
\hline GH-AJ608931- CSSV & 75 & 75 & 75 & 75 & 75 & 75 & 75 & 75 & 75 & 75 & 75 & 76 & 76 & 75 & 75 & 90 & 90 & 92 & 98 & 98 & 98 & 98 & 100 & & & & & & & \\
\hline GH-KX592575- CSSV & 75 & 75 & 75 & 75 & 76 & 75 & 76 & 75 & 76 & 75 & 75 & 76 & 76 & 75 & 75 & 90 & 90 & 92 & 98 & 98 & 97 & 98 & 99 & 100 & & & & & & \\
\hline Cl-KX592580- CSSV & 74 & 74 & 74 & 74 & 75 & 75 & 75 & 75 & 75 & 75 & 75 & 75 & 75 & 74 & 74 & 88 & 88 & 90 & 96 & 96 & 96 & 96 & 95 & 95 & 100 & & & & & \\
\hline Cl-KX592581- CSSV & 74 & 75 & 75 & 74 & 75 & 75 & 76 & 75 & 75 & 76 & 75 & 77 & 77 & 76 & 76 & 90 & 91 & 93 & 98 & 99 & 98 & 99 & 98 & 98 & 97 & 100 & & & & \\
\hline Cl-KX592582- CSSV & 74 & 75 & 75 & 74 & 75 & 75 & 75 & 75 & 75 & 75 & 75 & 76 & 76 & 76 & 75 & 90 & 90 & 92 & 98 & 98 & 97 & 98 & 98 & 98 & 96 & 98 & 100 & & & \\
\hline Cl-KX592583- CSSV & 74 & 74 & 75 & 74 & 75 & 75 & 75 & 75 & 75 & 75 & 75 & 77 & 76 & 75 & 75 & 90 & 90 & 93 & 98 & 99 & 98 & 98 & 98 & 98 & 96 & 99 & 99 & 100 & & \\
\hline Cl-KX59278- CSSV & 74 & 74 & 74 & 74 & 75 & 75 & 75 & 75 & 75 & 76 & 75 & 77 & 77 & 76 & 76 & 90 & 90 & 93 & 98 & 99 & 98 & 98 & 98 & 98 & 96 & 99 & 98 & 99 & 100 & \\
\hline Cl-KX592577- CSSV & 74 & 74 & 74 & 74 & 75 & 75 & 75 & 75 & 75 & 76 & 75 & 77 & 77 & 76 & 76 & 90 & 91 & 92 & 98 & 98 & 98 & 98 & 98 & 98 & 96 & 99 & 98 & 99 & 100 & 100 \\
\hline
\end{tabular}

Fig. 3. Pairwise nucleotide identity of the International Committee on the Taxonomy of Viruses (ICTV)-approved, taxonomically informative reverse-transcription ribonuclease $H$ sequence for 30 badnavirus isolates associated with cacao swollen shoot disease in West Africa. Sequences available in GenBank are indicated by the accession number. For each isolate, the country of origin is indicated by country code. Sequences were aligned using MUSCLE, implemented in Sequence Demarcation Tool v1.2 software, and $\geq 80 \%$ (highlighted) was used as the percent species cutoff, based on the ICTV guidelines for badnavirus taxonomy. Countries of origin and corresponding abbreviations for the isolates are $\mathrm{Cl}=$ Cote d'Ivoire, $\mathrm{GH}=$ Ghana, NIG = Nigeria, and TG = Togo. Virus species abbreviations are CRVBV = Cacao red vein-banding virus, CRVV = Cacao red vein virus, CSSCDV = Cacao swollen shoot CD virus, CSSV = Cacao swollen shoot virus, and CSSTAV = Cacao swollen shoot Togo A virus . 


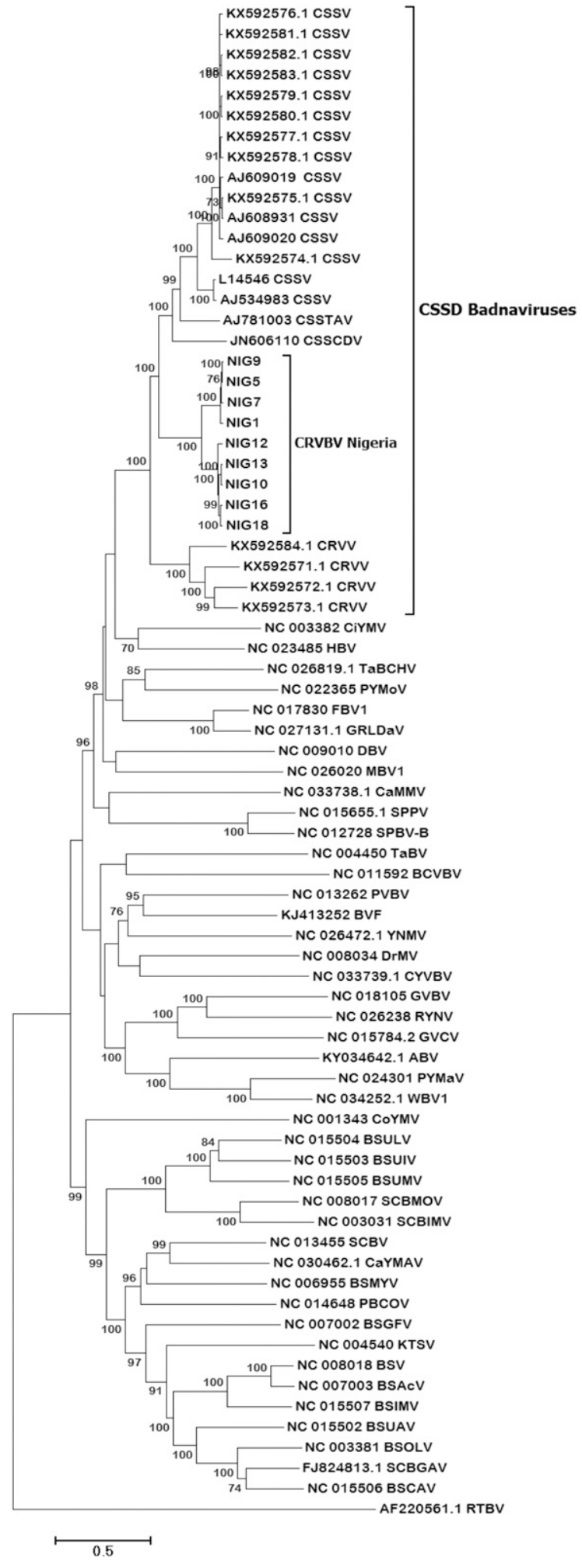

Fig. 4. A phylogenetic tree was reconstructed using the maximum likelihood for the full-length genome sequences of Cacao red vein-banding virus (CRVBV) isolates from Nigeria with 65 badnavirus sequences, representing 57 species available in the GenBank sequence database. Rice tungro bacilliform virus (RTBV) was included as the outgroup sequence. The horizontal branch lengths are proportional to genetic distance, and the values placed at the major nodes indicate $\geq 70 \%$ bootstrap support for 1,000 iterations. Badnavirus names and abbreviations are $\mathrm{BSCAV}=$ Banana streak CA virus, BsCVBV = Bougainvillea spectabilis chlorotic vein-banding virus, BSGFV = Banana streak GF virus, BSIMV = Banana streak $I M$ virus, $\mathrm{BSMYV}=$ Banana streak MY virus, BSOLV = Banana streak OL virus, BSUAV = Banana streak UA virus, BSUIV = Banana streak UI virus, BSULV = Banana streak UL virus, BSUMV = Banana streak UM virus, BSVAcV = Banana streak Vietnam Acuminata virus, BVF = Blackberry virus F, CaMMV = Cacao mild mosaic virus, CiYMV $=$ Citrus yellow mosaic virus, CoYMV $=$ Commelina yellow and by four domains on ORF3; namely a zinc finger-like domain associated with $\mathrm{CP}$, a pepsin-like AP, RT-LTR, and RNase H domains (Fig. 2). No CPDs were identified for proteins encoded by ORF2 and ORFY, using the CDD tool, an observation that is consistent with previously studied CSSD badnaviruses (Chingandu et al. 2017b).

Pairwise nucleotide analysis. Pairwise distance analysis of the taxonomically informative RT-RNase $\mathrm{H}$ region $(1,230 \mathrm{bp})$ and of the complete genome sequences indicated a shared nucleotide identify of 72 to 76 and 70 to $75 \%$, respectively, when compared with their closest relatives, comprising the four other CSSD badnaviral species recognized from West Africa $(n=21)$ (Fig. 3). In addition, the RT-RNase $\mathrm{H}$ region diverged from other well-characterized badnaviruses at $\leq 80 \%$ nucleotide identity, which falls below the ICTVapproved threshold for species demarcation in badnaviruses. Finally, based on the between-genome shared nucleotide identity, which ranged from 87 to $100 \%(n=9)$, the group of isolates from Nigeria are considered isolates of the same species.

Phylogenetic analysis. The ML analysis of the 74 available fulllength CSSD badnavirus genomes from West Africa placed all of the isolates together in one large clade, separate from other wellstudied badnaviruses (Fig. 4). And, within the CSSD-clade, the four previously recognized CSSD species and the newly described isolates from Nigeria grouped as robustly supported subclades, each with a $100 \%$ bootstrap value. These results underscore the previously reported high divergence among of cacao-infecting badnaviruses endemic to West Africa in relation to other known badnaviruses, and provide support for the recognition of at least five members of the CSSD complex thus far: the species CRVV, CSSCDV, CSSV, CSSTAV, and CRVBV (Fig. 4). Furthermore, the ML tree further resolved two subgroups in the CRVBV clade, indicative of two genetic variants, a result also corroborated by ML analysis of the IR fragments (preliminary results, above) (Dongo et al. 2018) and the $1068 \mathrm{bp}$ fragment within the movement protein region (Fig. 5). The two subgroups comprised CRVBV isolates collected from trees in the Osun or Oyo State, respectively, suggesting that the two genetic types have a history of geographic isolation. Interestingly, there was no relationship between isolate subgroup membership and foliar symptoms (Figs. 1 and 5), aside from the red vein-banding symptoms associated with all isolates for which a genome sequence could be obtained.

CRVBV-specific primer design and validation. An amplicon of the expected size, 1,068 bp, was obtained by PCR amplification for 16 of 18 Nigerian isolates, including the 9 samples previously found positive for badnavirus presence based on sequencing of the IR fragment (Dongo et al. 2018). The 1,086-bp fragment $(n=16)$ determined for the Oyo and Osun CRVBV subgroup isolates shared 93 to 99 and 92 to $98 \%$ nucleotide identities, respectively, indicating that within-subgroup divergences were similar and suggesting that the variants have coevolved in parallel isolation. No amplicon was obtained for the Osun samples NIG4 and NIG11, despite the observed foliar red vein-banding symptoms, although both isolates were also associated with foliar chlorosis symptoms (Fig. 1).

\section{Discussion}

Here, nine apparently full-length genome sequences representing a new CSSD-associated species in West Africa, herein named

mottle virus, $\mathrm{CRVV}=$ Cacao red vein virus, $\mathrm{CSSCDV}=$ Cacao swollen shoot $\mathrm{CD}$ virus, CSSTAV = Cacao swollen shoot Togo A virus, CSSV = Cacao swollen shoot virus, $\mathrm{CYVBV}=$ Cacao yellow vein-banding virus, $\mathrm{DBV}=$ Dioscorea bacilliform virus, $\mathrm{DMV}=$ Dracaena mottle virus, FBV1 = Fig badnavirus $1, \mathrm{GVBV}=$ Gooseberry vein banding virus, GVCV = Grapevine vein clearing virus, HBV = Hibiscus bacilliform virus, $\mathrm{KTSV}=$ Kalanchoe top spotting virus, $\mathrm{MBV} 1=$ Mulberry badnavirus $1, \mathrm{PBCoV}=$ Pineapple bacilliform comosus virus, $\mathrm{PVBV}=$ Pelargonium vein banding virus, $\mathrm{PYMoV}=$ Piper yellow mottle virus, RYNV = Rubus yellow net virus, SCBIMV = Sugarcane bacilliform IM virus, SCBMorV = Sugarcane bacilliform Mor virus, SCBV = Sugarcane bacilliform virus, SPBVA = Sweetpotato badnavirus $A$, SPBVB $=$ Sweetpotato badnavirus $B$, TBV $=$ Taro bacilliform virus, and PYMaV = Pagoda yellow mosaic associated virus. 
CRVBV, were determined from symptomatic cacao trees in Nigeria using PCR amplification, cloning, and Sanger sequencing. The initial BLASTn search (GenBank; 57 badnavirus genomes) results indicated that the genomes share their greatest similarity with the four previously recognized CSSD badnaviruses. This result was corroborated by the ML phylogeny, which groups the isolates from Nigeria (herein, CRVBV) as a sister clade to the four previously described CSSD Badnavirus spp., each representing a sister which, together, form a tight group. The CSSD badnagroup is well separated from all other well-studied badnaviruses, including three Badnavirus spp. known to infect cacao in Sri Lanka or the eastern Caribbean region (Chingandu et al. 2017b; Muller et al. 2018). The pairwise distances for the RT-RNase H locus sequences indicated that CRVBV isolates share 72 to $75 \%$ nucleotide identity (Fig. 3), well below the $\geq 80 \%$ nucleotide threshold used for Badnavirus sp. demarcation (King et al. 2012). Taken together, the results of the partial and complete genome sequence analyses (e.g., pairwise distance and reconstructed phylogenetic tree) provide robust evidence that CRVBV is sufficiently divergent from all previously described badnaviruses to be recognized as a new species, for which the name Cacao red

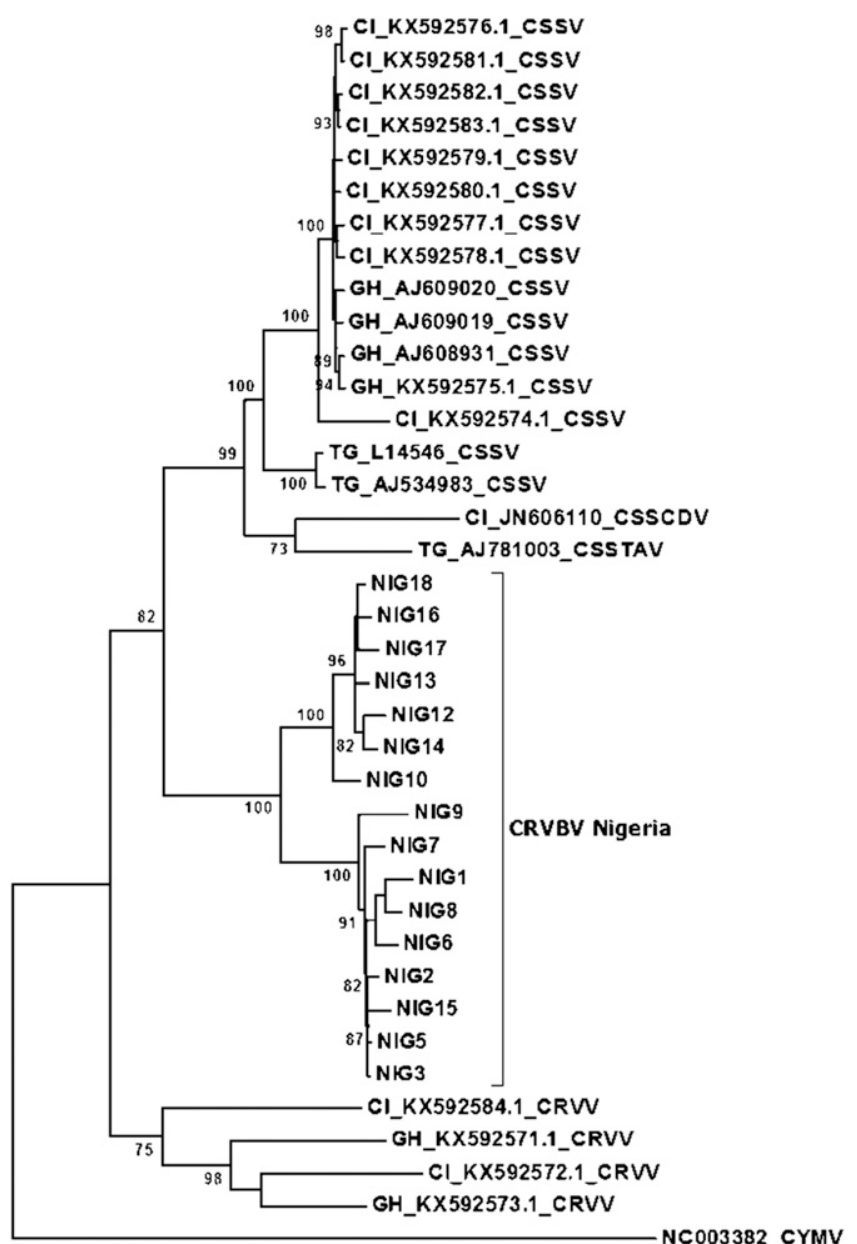

02

Fig. 5. Maximum-likelihood phylogenetic analysis of the approximately 1-kbp region (alignment coordinates 1,734 to 2,802) amplified using the newly designed Cacao red vein-banding virus (CRVBV) diagnostic primers for the 16 isolates from Nigeria. Twenty-one full-length sequences in GenBank previously isolated are indicated with country of collection, GenBank accession number, and virus species. Citrus yellow mosaic virus (CYMV) was included as the outgroup. Horizontal branch lengths are proportional to genetic distance, and values placed at the major nodes indicate $\geq 70 \%$ bootstrap support for 1,000 iterations. Country origins are abbreviated as follows: $\mathrm{Cl}=$ Cote d'lvoire, $\mathrm{GH}=$ Ghana, $\mathrm{NIG}=$ Nigeria, and $\mathrm{TG}=$ Togo. Virus species abbreviations are CRVBV $=$ Cacao red vein-banding virus, $\mathrm{CRVV}=$ Cacao red vein virus, $\mathrm{CSSCDV}=$ Cacao swollen shoot $\mathrm{CD}$ virus, $\mathrm{CSSV}=$ Cacao swollen shoot virus, and CSSTAV = Cacao swollen shoot Togo A virus . vein-banding virus is proposed. This discovery makes CRVBV the fifth presumed endemic, cacao-infecting badnaviral species extant in West Africa.

In Nigeria, the discovery marks the first report of an apparently full-length CSSD-like genome sequence determined from cacao trees showing foliar red vein banding together with a range of secondary symptoms, corroborating the observation of swollen shoot symptoms in cacao in Nigeria since 1944. It is important to point out that virus particles have not yet been observed in CRVBV-infected cacao samples, nor has the possibility been ruled out that the CRVBV genome sequences could represent episomal genomes of endogenous badnaviruses, resulting from genome-integration events (Chabannes and Iskra-Caruana 2013; Geering et al. 2014). Experiments are currently underway to seek evidence for the possible genomic integration of CSSD badnaviruses into cacao.

Within the CRVBV species itself, two statistically well-supported subgroups were resolved, each tightly linked by geographic origin in Osun or Oyo, respectively (Fig. 4), an observation that is reminiscent of a natural- or human-imposed barrier that appears to have given rise to their parallel diversification in isolation. Although CRVBV is the most divergent member of the CSSD complex, it is nonetheless most closely related to the other badnaviruses causing swollen shoot disease of cacao in West Africa, referred to hereafter as CSSD badnaviruses. The ability to cause symptoms of shoot swellings, foliar discoloration, and decline, together with extensive genomic divergence, sets the CSSD badnaviruses apart from cacao-infecting badnaviruses identified in Trinidad (Chingandu et al. 2017c) and a new species discovered recently in Sri Lanka (Muller et al. 2018) (Fig. 4). These collective results support the hypothesis that CRVBV and the other four CSSD badnaviruses have a West African origin where, to date, their distribution is thought to be confined. Finally, the CSSD complex exhibits moderate to high intraspecific divergences (e.g., from 72 to $99 \%$ among the five recognized species CRVBV, CRVV, CSSTAV, CSSCDV, and CSSV), a range that is comparable with that observed among the Banana streak virus complex of species (Harper et al. 2005), another group of badnaviruses associated with a cultivated plant host that are more closely related to each other than to other extant badnaviruses.

Although the lengths of CRVBV genomes are shorter, at approximately 6,820 to 6,933 bp in size, compared with previously described CSSD badnaviral genomes of approximately 7,000 to 7,300 , CRVBV genomes encode the canonical badnaviral ORFs 1, 2,3 , and Y. And, as with other badnaviruses, they encode the predicted CPDs: zinc knuckle CP motif, pepsin-like AP, RT, and RNase $\mathrm{H}$ (Fig. 2). However, unlike most other badnaviruses, CRVBV and CRVV encode four ORFs (Chingandu et al. 2017b), whereas CSSCDV, CSSV, and CSSTAV (e.g., the "core CSSD species") encode five or six ORFs (Muller and Sackey 2005). In addition, the CSSD badnaviruses share in common a number of CPDs, which may harbor important clues about specific mechanisms involved in cacao host-viral pathogen interactions leading to uniquely CSSD symptoms, most notably shoot swelling.

Although Koch's postulates have not been completed for CRVBV to determine causality of CSSD, the "constant association" of CRVBV-like genomes with symptomatic cacao trees there provides the first direct knowledge about virus identity and extent of genomic variability among CSSD badnaviruses in Nigeria. Based on genomic sequences, PCR primers are available for the first time for detection of CRVBV that target an approximately 1-kbp fragment of the $5^{\prime}$ end of ORF3 which, among samples tested herein, resulted in $88.8 \%$ detection. Their inability to detect suspect badnavirus in 2 of the 18 symptomatic trees that showed foliar chlorosis symptoms (Fig. 1) may have been due to several factors, including sample quality, difference in tree genotype or age that might influence virus titer, or infection by unreported badnaviruses or perhaps nonbadnaviruses.

Tools for CSSD badnavirus detection and differentiation among species and strains have become essential for the success of West African cacao breeding programs currently striving to develop badnavirus-resistant cacao, and for elucidating the regional 
phylodynamics of CSSD to aid in disease management. Ultimately, CSSD-resistant cacao genotypes are needed to protect newly planted trees from this debilitating disease while, at the same time, reducing virus inoculum levels overall. Durable virus disease resistance, together with improved mealybug vector control, is expected to aid in reducing the spread of CSSD viruses into and between neighboring cacao farms, and of new CSSD species and strains associated with the endemic flora, toward long-term CSSD management.

\section{Literature Cited}

Abrokwah, F., Dzahini-Obiatey, H., Galyuon, I., Osae-Awuku, F., and Muller, E. 2016. Geographical distribution of Cacao swollen shoot virus molecular variability in Ghana. Plant Dis. 100:2011-2017.

Adegbola, M. O. K. 1975. The reaction of four Nigerian isolates of CSSV on the germination and growth of cacao seedlings under different environmental conditions. Pages 338-343 in: Proc. 5th Int. Cocoa Res. Conf. Ibadan, Nigeria.

Ameyaw, G. A., Chingandu, N., Domfeh, O., Dzahini-Obiatey, H. K., Gutierrez, O. A., and Brown, J. K. 2018. Variable detection of Cacao swollen shoot disease-associated badnaviruses by PCR amplification. In: Proc. Int. Symp. Cocoa Res. T3-Pests Dis. Lima, Peru.

Ameyaw, G. A., Wetten, A., Dzahini-Obiatey, H., Domfeh, O., and Allainguillaume, J. 2013. Investigation on Cacao swollen shoot virus (CSSV) pollen transmission through cross-pollination. Plant Pathol. 62:421-427.

Attafuah, A., and Glendinning, D. K. 1965a. Studies on resistance and tolerance to cocoa viruses in Ghana. Ann. Appl. Biol. 56:219-225.

Attafuah, A., and Glendinning, D. K. 1965b. Studies on resistance and tolerance to cocoa viruses in Ghana. II. A survey of breeding material. Ann. Appl. Biol. 56:227-230.

Bartley, B. G. D. 2005. The Genetic Diversity of Cacao and Its Utilization. CABI Publishing, Wallingford, Oxfordshire, U.K.

Brunt, A. A. 1964. Some properties of Cacao swollen shoot virus. J. Gen. Microbiol. 36:303-309.

Chabannes, M., and Iskra-Caruana, M.-L. 2013. Endogenous pararetrovirusesReservoirs of virus infection in plants. Curr. Opin. Virol. 3:615-620.

Chingandu, N., Kouakou, K., Aka, R., Ameyaw, G., Gutierrez, O. A., Herrmann, H., and Brown, J. K. 2017a. The proposed new species, Cacao red vein virus, and three previously recognized badnavirus species are associated with cacao swollen shoot disease. Virol. J. 14:199.

Chingandu, N., Kouakou, K., Aka, R., Gutierrez, O. A., and Brown, J. K. 2017b. Unexpected genome variability at multiple loci suggests Cacao swollen shoot virus comprises multiple, divergent molecular variants. J. Emerg. Dis. Virol. 3:1-10.

Chingandu, N., Zia-ur-rehman, M., Sreenivasan, T. N., Surujdeo-Maharaj, S., Umaharan, P., Gutierrez, O. A., and Brown, J. K. 2017c. Molecular characterization of previously elusive badnaviruses associated with symptomatic cacao in the New World. Arch. Virol. 162:1363-1371.

Dongo, L., Chingandu, N., and Brown, J. K. 2018. Molecular genomic diversity of previously undescribed cacao swollen shoot badnaviruses in Nigeria. Pages 13-17 in: Proc. 2017 Int. Symp. Cocoa Res. T3-Pests Dis. Lima, Peru.

Dongo, L. N., Ohunakin, A. O., Atiri, G. I., and Kumar, P. L. 2012. Assessment of the impact of Cacao swollen shoot virus in Nigeria and development of simple diagnostic tools. In: Proc. 17th Int. Cocoa Res. Conf. Alliance of Cocoa Producing Countries (COPAL). Lagos, Nigeria, Yaounde.

Dongo, L. N., and Orisajo, S. B. 2007. Status of cocoa swollen shoot virus disease in Nigeria. Afr. J. Biotechnol. 6:2054-2061.

Doyle, J. J., and Doyle, J. L. 1990. Isolation of plant DNA from fresh tissue. Focus (Madison) 12:13-15.

Edgar, R. C. 2004. MUSCLE: Multiple sequence alignment with high accuracy and high throughput. Nucleic Acids Res. 32:1792-1797.

Edward, R., and Wetten, A. 2016. Virus detection and elimination in cocoa (Theobroma cacao L.) through somatic embryogenesis. J. Plant Sci. 4:52-57.

Friscina, A., Chiappetta, L., Jacquemond, M., and Tepfer, M. 2017. Infection of non-host model plant species with the narrow-host-range Cacao swollen shoot virus. Mol. Plant Pathol. 18:293-297.

Geering, A. D. W., Maumus, F., Copetti, D., Choisne, N., Zwickl, D, J., Zytnicki, M., McTaggart, A. R., Scalabrin, S., Vezzulli, S., Wing. R. A., Quesneville, H., and Teycheney, P.-V. 2014. Endogenous florendoviruses are major components of plant genomes and hallmarks of virus evolution. Nat. Commun. 5:5269.

Hagen, L. S., Lot, H., Godon, C., Tepfer, M., and Jacquemond, M. 1994. Infection of Theobroma cacao using cloned DNA of Cacao swollen shoot virus and particle bombardment. Phytopathology 84:1239-1243.

Harper, G., Hart, D., Moult, S., Hull, R., Geering, A., and Thomas, J. 2005. The diversity of Banana streak virus isolates in Uganda. Arch. Virol. 150:2407-2420.

Jacquot, E., Hagen, L. S., Jacquemond, M., and Yot, P. 1996. The open reading frame 2 product of Cacao swollen shoot badnavirus is a nucleic acid-binding protein. Virology 225:191-195.

Jacquot, E., Hagen, L. S., Michler, P., Rohfritsch, O., Stussi-Garaud, C., Keller, M., Jacquemond, M., and Yot, P. 1999. In situ localization of Cacao swollen shoot virus in agroinfected Theobroma cacao. Arch. Virol. 144:259-271.
Kenten, R. H., and Legg, J. T. 1970. Methods for assessing the tolerance and resistance of different types of cocoa to cocoa swollen-shoot virus. Ann. Appl. Biol. 65:419-424.

King, A. M. Q., Adams, M. J., Carstens, E. B., and Lefkowitz, E. J., eds. 2012. Family Caulimoviridae. Pages 438-440 in: Virus Taxonomy. Ninth Report of the International Committee on Taxonomy of Viruses. Elsevier Academic Press, London, U.K.

Kouakou, K., Kébé, B. I., Kouassi, N., Aké, S., Cilas, C., and Muller, E. 2012. Geographical distribution of Cacao swollen shoot virus molecular variability in Côte d'Ivoire. Plant Dis. 96:1445-1450.

Lister, R. M., and Thresh, J. M. 1956. Annual Report of the West African Cocoa Research Institute, 1955-1956.

Lister, R. M., and Thresh, J. 1957. The history and control of cocoa swollen shoot disease in Nigeria. Pages 132-142 in: Cocoa, Chocolate and Confectionery Alliance Ltd. Rep. Cocoa Conf. London, U.K.

Mangenot, G., Alibert, H., and Basset, A. 1946. Sur les caracteres du swollen shoot en Cote d'Ivoire. Rev. Int. Bot. Appl. Paris 283:13.

Marchler-Bauer, A., Derbyshire, M. K., Gonzales, N. R., Lu, S., Chitsaz, F., Geer L. Y., Geer, R. C., He, J., Gwadz, M., Hurwitz, D. I., Lanczycki, C. J., Lu, F., Marchler, G. H., Song, J. S., Thanki, N., Wang, Z., Yamashita, R. A., Zhang, D., Zheng, C., and Bryant, S. H. 2015. CDD: NCBI's conserved domain database. Nucleic Acids Res. 43:D222-D226.

Muhire, B. M., Varsani, A., and Martin, D. P. 2014. SDT: A virus classification tool based on pairwise sequence alignment and identity calculation. PLoS One 9:e108277.

Muller, E. 2015. Creation of four new species in the genus Badnavirus. Int. Comm Taxon. Viruses ICTV. https://talk.ictvonline.org/ICTV/proposals/2015.026aP. A.v2.Badnavirus_4sp.pdf

Muller, E., Jacquot, E., and Yot, P. 2001. Early detection of Cacao swollen shoot virus using the polymerase chain reaction. J. Virol. Methods 93: 15-22.

Muller, E., Ravel, S., Agret, C., Abrokwah, F., Dzahini-Obiatey, H., Galyuon, I., Kouakou, K., Jeyaseelan, E. C., Allainguillaume, J., and Wetten, A 2018. Next generation sequencing elucidates cacao badnavirus diversity and reveals the existence of more than ten viral species. Virus Res. 244: 235-251

Muller, E., and Sackey, S. 2005. Molecular variability analysis of five new complete Cacao swollen shoot virus genomic sequences. Arch. Virol. 150: 53-66.

Murray, D. F. 1945. First progress report of the Nigerian Cocoa Survey.

Obok, E., Wetten, A., and Allainguillaume, J. 2018. Molecular evidence of Cacao swollen shoot virus acquisition and retention by Planococcus citri (Risso) and Pseudococcus longispinus (Targioni-Tozzetti) and Pseudococcus viburni (Signoret) mealybugs (Hemiptera: Pseudococcidae). Int. J. Sci. Res. Publ. 8: 34-44.

Ollennu, L. A. A., and Owusu, G. K. 2003. Field evaluation of the protective capacity of CSSV mild strain N1 against severe strain New Juaben (1A) isolate. Ghana J. Agric. Sci. 36:3-12.

Oro, F., Mississo, E., Okassa, M., Guilhaumon, C., Fenouillet, C., Cilas, C., and Muller, E. 2012. Geographical differentiation of the molecular diversity of Cacao swollen shoot virus in Togo. Arch. Virol. 157:509-514.

Partiot, M., Amefia, Y. K., Djiekpor, E. K., and Bakar, K. A. 1978. Le swollen shoot du cacaoyer au Togo. Investaire preliminaire et premiere estimation des pertes causees par la maladie. Cafe-cacao Thea 22:217-228.

Ploetz, R. C. 2007. Cacao diseases : Important threats to chocolate production worldwide. Phytopathology 97:1634-1639.

Posnette, A. F. 1950. Virus diseases of cacao in West Africa. VII. Virus transmission by different vector species. Ann. Appl. Biol. 37:378-384.

Posnette, A. F., and Strickland, A. H. 1948. Virus diseases of cacao in West Africa. III. Technique of insect transmission. Ann. Appl. Biol. 35:53-63.

Posnette, A. F., and Todd, J. M. 1951. Virus diseases of cacao in West Africa. VIII The search for virus-resistant cacao. Ann. Appl. Biol. 38:785-800.

Quainoo, A. K., Wetten, A. C., and Allainguillaume, J. 2008. Transmission of cocoa swollen shoot virus by seeds. J. Virol. Methods 150:45-49.

Roivainen, O. 1976. Transmission of cocoa viruses by mealybugs (Homoptera: Pseudococcidae). J. Sci. Agric. Soc. Finl. 48:203-304.

Sagemann, W., Paul, H. L., Adomako, D., and Owusu, G. K. 1983. The use of enzyme-linked immunosorbent assay (ELISA) for detection of Cacao swollen shoot virus (CSSV) in Theobroma cacao. J. Phytopathol. 106:281-284.

Steven, W. F. 1936. A new disease of cocoa in the Gold Coast. Trop. Agric Trinidad 14:84

Tamura, K., Stecher, G., Peterson, D., Filipski, A., and Kumar, S. 2013. MEGA6: Molecular evolutionary genetics analysis version 6.0. Mol. Biol. Evol. 30: $2725-2729$

Thresh, J. 1960. Cacao virus research in Nigeria. Separado Turrialba 10:57-63.

Thresh, J. M. 1958. The spread of virus disease in cacao. West Afr. Cocoa Res. Inst. Tech. Bull. 5:36.

Yang, I. C., Hafner, G. J., Revill, P., Dale, J. L., and Harding, R. M. 2003 Sequence diversity of South Pacific isolates of Taro bacilliform virus and the development of a PCR-based diagnostic test. Arch. Virol. 148: 1957-1968. 
ERRATUM / Volume 103, Number 8, 2019 / PDIS-09-18-1561-RE

In the article, "The Previously Unidentified, Divergent Badnavirus Species Cacao red vein-banding virus is Associated with Cacao Swollen Shoot Disease in Nigeria" by Nomatter Chingandu, Lelia Dongo, Osman A. Gutierrez, and Judith K. Brown, some additional information was left out. This erratum addresses the inclusion of a badnaviral-like genome sequence determined by Illumina sequencing (unverified by Sanger sequencing) (Muller et al. 2018; Virus Res. 244:235-251) to our phylogenetic analysis reported in Plant Disease (https://doi.org/10.1094/PDIS-09-18-1561-RE, Chingandu et al. 2019) from which it was inadvertently omitted. The MF642724 accession is of an isolate, arbitrarily 'M', determined from a cacao plant sampled in Ghana. The results indicate that the ' $\mathrm{M}$ ' genome sequence groups with one of two subclades harboring genome sequences for the newly proposed badnavirus species, Cacao red vein banding virus (Dongo et al. 2018), determined by bidirectional Sanger sequencing of cloned viral genomes $(n=9)$. The addition of the ' $M$ ' accession did not change the conclusion reached in our study, which represents the first report of CRVBV as a previously undescribed badnavirus species associated with swollen shoot diseased cacao plants in Nigeria. The ' $M$ ' sequence determined exclusively by Illumina sequencing (but treated differently from the Sanger sequences also reported in the Muller et al. 2018 paper) from a cacao plant in Ghana, grouped with one of the two CRVBV subgroups resolved by our CRVBV-ML analysis. Virus-infected cacao plants are known to be transported within and between cacaogrowing countries worldwide, and/or by mealybug vectors that can disperse long distances, making it difficult to determine the exact origin(s) of the 'M'-Ghana or CRVBV-Nigeria isolates. Such a determination will require genome sequences for diverse badnavirus isolates infecting cacao and understory plants of West African endemism that are presumed to harbor co-evolved the badnaviruses, which made a host-jump to cacao after it was introduced into West Africa from the Amazon Basin/Caribbean for cultivation in the late 1800 s to early 1900 s. The nine CRVBV genomes identified from cacao in Nigeria, and exhibiting symptoms described in the early literature, grouped as two divergent subclades and showed significant intra-genomic variability. Although these results are suggestive of Nigerian endemism, and thereby implicate badnaviruses coevolved with host plants native to Nigeria as the closest extant CRVBV-relatives, these hypotheses remain to be tested.

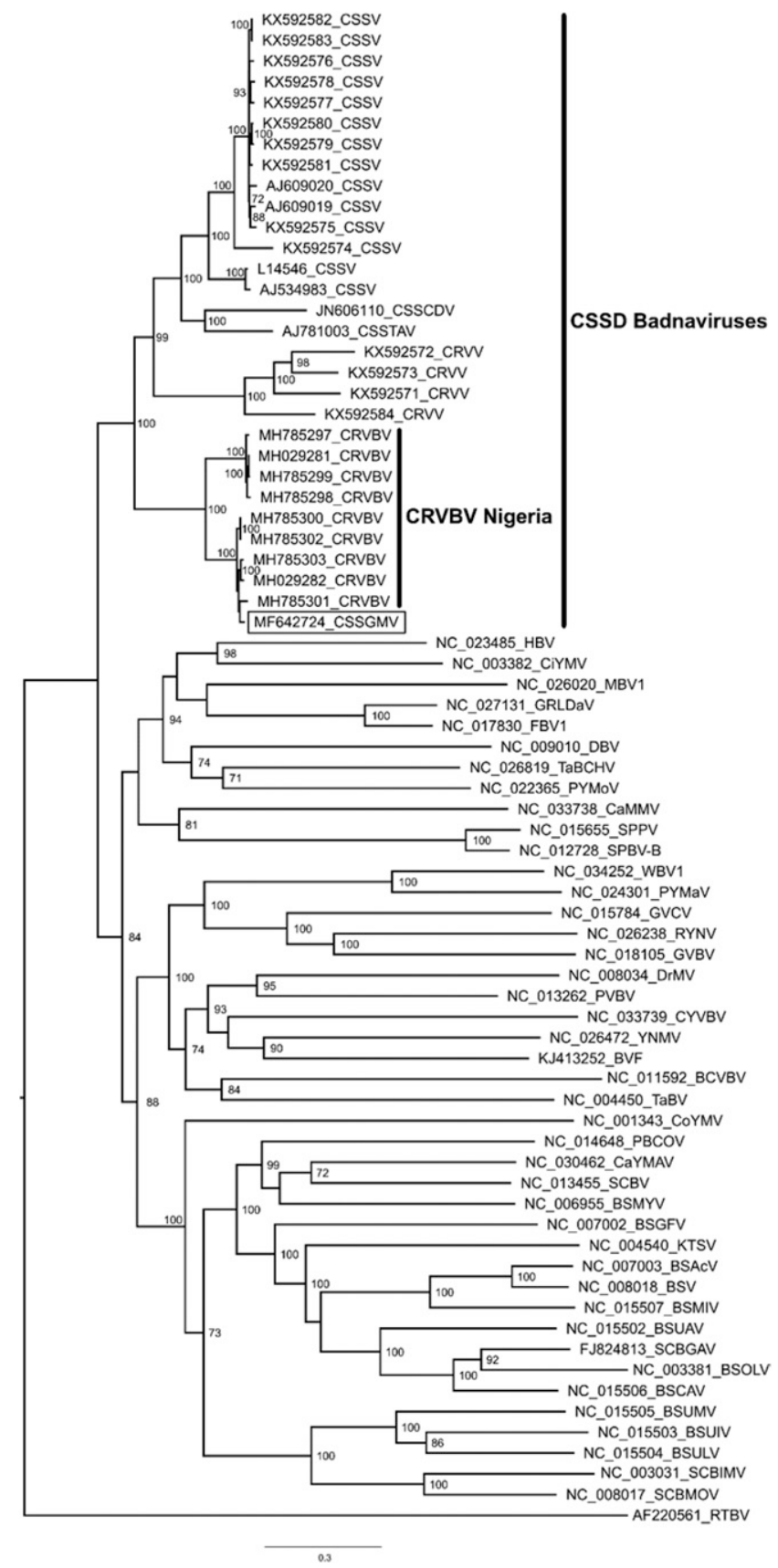

Supporting Material. Results of a phylogenetic analysis of nine isolates (two subclades, perhaps 'strains') of the (proposed) Cacao red vein-banding virus species from Nigeria, with GB accession MF642724, and representative badnaviral genome sequences available in the GenBank database. The tree was reconstructed in the RaxML program using the maximum likelihood (ML) method and 1,000 bootstraps and $\mathrm{GTR}+\mathrm{G}+\mathrm{l}$ as substitution model and edited using FigTree and Inkscape. The bootstrap values $\geq 70$ for 1,000 iterations are shown at the major nodes. The isolate ' $M$ ' from Ghana (accession no. MF642724) (after manual editing) included in this tree is boxed, was found to be phylogenetically most closely related to the nine CRVBV isolates from Nigeria, among known badnaviruses. 